\title{
Thermodynamics of reaction of praseodymium with gallium-indium eutectic alloy
}

\author{
S.Yu. Melchakov ${ }^{\text {a,* }}$, V.A. Ivanov ${ }^{\text {a }}$, L.F. Yamshchikov ${ }^{\text {a }}$, V.A. Volkovich ${ }^{a}$, A.G. Osipenko ${ }^{\text {b }}$ M.V. Kormilitsyn ${ }^{\text {b }}$ \\ ${ }^{a}$ Department of Rare Metals and Nanomaterials, Institute of Physics and Technology, Ural Federal University, Ekaterinburg 620002, Russian Federation \\ b JSC "State Scientific Centre - Research Institute of Atomic Reactors", Dimitrovgrad 433510, Russian Federation
}

\section{A R T I C L E I N F O}

\section{Article history:}

Received 30 October 2012

Accepted 1 February 2013

Available online 8 February 2013

\begin{abstract}
A B S T R A C T
Thermodynamic properties of Ga-In eutectic alloys saturated with praseodymium were determined for the first time employing the electromotive force method. The equilibrium potentials of the Pr-In alloys saturated with praseodymium (8.7-12.1 mol.\% Pr) and Pr-Ga-In alloys (containing 0.0012-6.71 mol.\% Pr) were measured between 573-1073 K. Pr-In alloy containing solid PrIn 3 with known thermodynamic properties was used as the reference electrode when measuring the potentials of ternary Pr-In-Ga alloys. Activity, partial and excessive thermodynamic functions of praseodymium in alloys with indium and GaIn eutectic were calculated. Activity $(a)$, activity coefficients $(\gamma)$ and solubility $(X)$ of praseodymium in the studied temperature range can be expressed by the following equations:

$\lg a_{\alpha-\operatorname{Pr}(\mathrm{In})}=4.425-11965 / T \pm 0.026$.

$\lg a_{\alpha-\operatorname{Pr}(\mathrm{Ga}-\mathrm{In})}=5.866-14766 / T \pm 0.190$.

$\lg \gamma_{\alpha-\operatorname{Pr}(\mathrm{Ga}-\mathrm{In})}=2.351-9996 / \mathrm{T} \pm 0.39$.

$\lg X_{\mathrm{Pr}(G \mathrm{G}-\mathrm{In})}=3.515-4770 / T \pm 0.20$.
\end{abstract}

(c) 2013 Elsevier B.V. All rights reserved.

\section{Introduction}

Molten salts and liquid metals can be employed as prospective working media for developing non-aqueous pyrochemical methods of reprocessing spent nuclear fuels (SNFs). Exceptionally high thermal and neutron stability of these inorganic liquids allows reprocessing SNF with high burn-up and short cooling time, the main requirements for achieving a short closed nuclear fuel cycle. Highly irradiated fuel of fast neutron reactors can also be reprocessed employing pyrochemical methods. Development and optimization of pyrochemical technologies is impossible without detailed information on thermodynamic properties of the elements comprising spent fuels in fused salts and metals. Rare earth metals (yttrium and elements from lanthanum to dysprosium) represent an important group of fission products present in SNF arriving for reprocessing. Understanding their behaviour in all stages of the reprocessing is essential for designing a feasible technology. Low-melting group III metals have attracted particular attention for separating SNF components, e.g., by selective extraction from fused salt into a liquid metal phase. Using metallic alloys of eutectic compositions allows reduction of working temperatures but the thermodynamic properties of ternary systems containing two low melting metals and an SNF element are essentially unknown. Thermodynamic estimates show that gallium and aluminium are efficient in separating uranium and lanthanide fission products in $3 \mathrm{LiCl}-2 \mathrm{KCl}$ based melts. Low melting points of gallium based

\footnotetext{
* Corresponding author. Tel.: +7 9126893893; fax: +7 3433754154 .

E-mail address: stanie_melchakov@mail.ru (S.Yu. Melchakov).
}

eutectics (e.g., Ga-In with m.p. of $289 \mathrm{~K}$ or Ga-Al with m.p. of $299 \mathrm{~K}$ [1]) allow reduction of working temperatures and simplification of technological equipment. Praseodymium is one of the rare earth group fission products and one tonne of SNF contains around $2.8 \mathrm{~kg}$ of Pr. Behaviour of rare earth fission products, including Pr, in binary low melting metallic alloys so far was not investigated and the present work was aimed at studying the thermodynamic properties of praseodymium in gallium-indium eutectic based alloys.

\section{Experimental}

The experiments were performed at 573-1073 K under argon atmosphere in the experimental cell schematically shown in Fig. 1. Argon was additionally purified by passing several times through zirconium turnings heated to $973 \mathrm{~K}$. The electromotive force (EMF) of the galvanic cell:

$$
(-) \text { Liquid }+\operatorname{PrIn}_{3}\left|\mathrm{LiCl}-\mathrm{KCl}-\mathrm{CsCl}+\mathrm{PrCl}_{3}\right| \mathrm{Pr}-\mathrm{Ga}-\mathrm{In}(+)
$$

was measured at zero current employing an Autolab PGStat $302 \mathrm{~N}$ potentiostat/galvanostat. Ternary eutectic mixture of lithium, potassium and cesium chlorides (57.5-16.5-26 mol.\%, m.p. $536 \mathrm{~K}$ ) acted as low melting salt electrolyte. Analytical grade individual anhydrous alkali chlorides were dried under vacuum for several hours prior to melting. Molten salts were sparged by gaseous hydrogen chloride to convert trace oxide impurities into chlorides. After such preliminary treatment the salts were fused in the required ratio for preparing the eutectic. Praseodymium containing melts were obtained by reacting praseodymium oxide, $\operatorname{Pr}_{6} \mathrm{O}_{11}$, with 


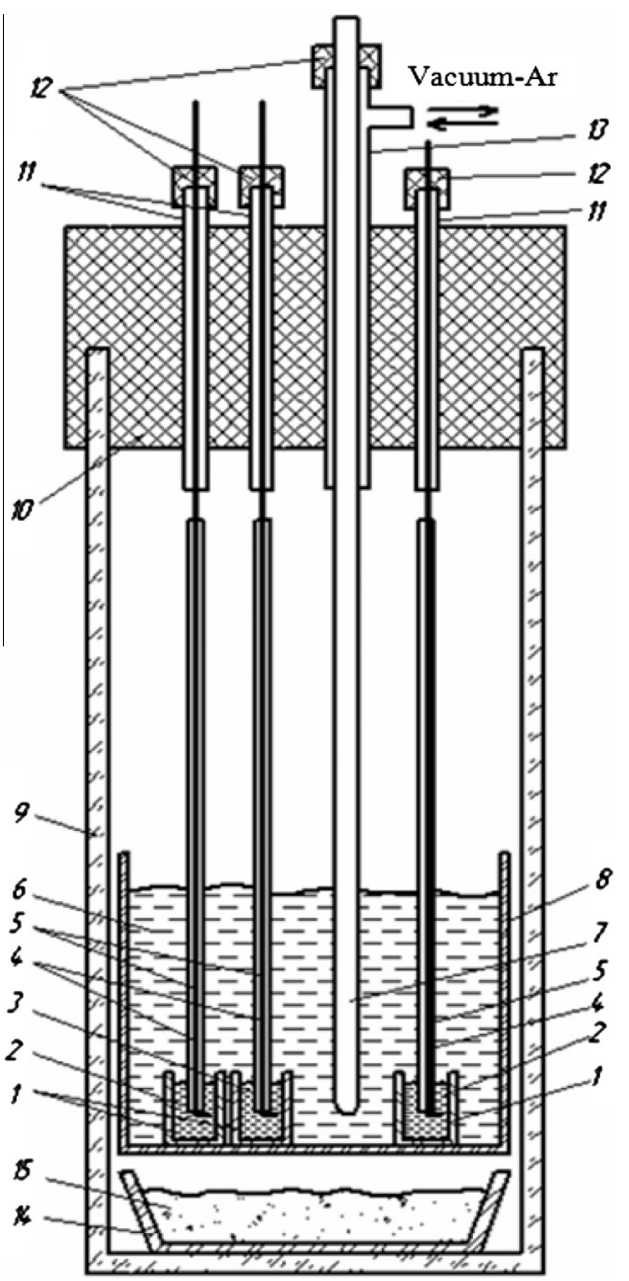

Fig. 1. Experimental cell. 1 - small BeO crucibles; 2 -liquid alloys; 3 - two-phase liquid reference electrode (In $\left.+\operatorname{PrIn}_{3}\right) ; 4$ - tungsten wire current conductors; 5 alumina tubes; 6 - electrolyte; 7 - BeO thermocouple sheath; 8 - large $\mathrm{BeO}$ crucible; 9 - cell body; 10 - lid; 11,13 - silica tubes; 12 - rubber stoppers; 14 alumina crucible; and 15 - zirconium turnings getter.

hydrogen chloride directly in the fused ternary eutectic. Concentration of praseodymium in the melts was determined by complexometric titration [2]. Ready-to-use praseodymium containing salt mixtures ( $\mathrm{LiCl}-\mathrm{KCl}-\mathrm{CsCl}-\mathrm{PrCl}_{3}, \mathrm{Ca} .2 \mathrm{wt}$.\% Pr) were stored in an inert atmosphere dry box (MBraun UniLab 1200/780). Oxygen and water content in the dry box atmosphere were below $0.1 \mathrm{ppm}$.

Ga-In eutectic alloys ( $21.8 \mathrm{wt}$.\% indium) were prepared by fusing individual metals at $50{ }^{\circ} \mathrm{C}$ for two weeks under argon. For the experiment (all preparations was carried out in the inert atmosphere dry box), a $2 \mathrm{~cm}^{3}$ portion of the liquid alloy was introduced into a small beryllium oxide crucible, weighed, and the required amount of metallic praseodymium (Alfa Aesar) added. Crucibles (up to twenty at a time) were positioned in a large beryllium oxide crucible ( $\mathrm{ca} .300 \mathrm{~cm}^{3}$ volume). Tungsten wire current conductors were inserted into the small crucibles and the large crucible was charged with pieces of solid $\mathrm{LiCl}-\mathrm{KCl}-\mathrm{CsCl}-\mathrm{PrCl}_{3}$ mixture prepared in advance. Liquid alloys containing less than $0.8 \mathrm{wt}$.\% Pr were prepared directly in the experimental cell by cathodically depositing praseodymium on Ga-In eutectic; praseodymium-rich Pr-In alloy served as an anode.

After assembling and closing the experimental cell it was taken out of the dry box, positioned in a vertical resistance tube furnace with automatic temperature control, heated to 923-973 K and kept at this temperature for $12 \mathrm{~h}$ to homogenize the alloys. To purify the atmosphere in the cell from residual oxygen and moisture zirconium turnings (acting as a getter) were placed in the bottom part of the cell, see Fig. 1. Having heated $\mathrm{Zr}$ getter inside the cell ensured that concentrations of oxygen and water during the experiment were kept negligibly low. For the duration of the experiment the experimental cell was connected to an expandable gas receiver thus maintaining the internal pressure at one atmosphere. The electrode potentials were measured relative to twophase Pr-In alloy, containing solid $\operatorname{PrIn}_{3}$. Praseodymium content in the reference electrode (8.7-12.1 mol.\% $\mathrm{Pr}$ ) corresponded to the two-phase region of the $\mathrm{Pr}$-In system [1], i.e., to a saturated solution of $\mathrm{Pr}$ in indium in equilibrium with $\operatorname{PrIn}_{3}$ intermetallic compound. At a chosen temperature the equilibrium potentials of the alloys were recorded if they did not show a tendency to a monotonous shift and varied by no more than $0.1-0.5 \mathrm{mV}$ for an hour. The potentials of the alloys of the same phase composition were reproducible with an accuracy of $\pm 0.1-0.2 \mathrm{mV}$. During a single experiment the measurements were done over $573-1073 \mathrm{~K}$ temperature range, the temperature was changed several times from the highest value to the lowest and back in steps of 30$50 \mathrm{~K}$. The temperature was measured by a K-type thermocouple placed directly into the melt in a beryllium oxide sheath. After the experiment the cell was cooled, quenched salts dissolved and the alloys washed with ice-cold deionized water and analyzed for praseodymium content by ICP-MS (Perkin Elmer ELAN 9000).

\section{Results and discussion}

\subsection{Activity of praseodymium in In and Ga-In eutectic alloys}

In a first series of experiments the potential of the two-phase Pr-In reference electrode (Liquid $+\operatorname{PrIn}_{3}$ ) was measured $v s$. praseodymium metal employing the following galvanic cell:

$(-) \operatorname{Pr}\left|\mathrm{LiCl}-\mathrm{KCl}-\mathrm{CsCl}+\operatorname{PrCl}_{3}\right|$ Liquid $+\operatorname{PrIn}_{3}(+)$

Since praseodymium undergoes an $\alpha$ - $\operatorname{Pr} \rightarrow \beta$-Pr phase transformation at $1069 \mathrm{~K}$ the appropriate correction was made to the value of the EMF obtained at temperatures above the transition point [3]. The experimental dependence $E=f(T)$ of the electrochemical cell (2) at $573-1073 \mathrm{~K}$ is satisfactorily approximated by the linear equation:

$$
\begin{gathered}
E=0.7914-0.2927 \times 10^{-3} T \pm 0.0116, V ; \\
\quad\left(S_{\text {res }}^{2}=3.15 \times 10^{-5}, V^{2}\right),
\end{gathered}
$$

where $S_{\text {res }}^{2}$ is the residual dispersion.

To calculate activity of praseodymium the following procedure was employed. The galvanic cell (2) can be considered as a combination of two cells with the chlorine reference electrode:

$$
\begin{aligned}
& (+) \operatorname{Pr}\left|\mathrm{LiCl}-\mathrm{KCl}-\mathrm{CsCl}+\mathrm{PrCl}_{3}\right| \mid \mathrm{LiCl}-\mathrm{KCl}-\mathrm{CsCl}_{\mid \mathrm{Cl}_{2}(\mathrm{C})(-)} \\
& (+) \mathrm{Liquid}+\mathrm{PrIn}_{3}(-)\left|\mathrm{LiCl}-\mathrm{KCl}-\mathrm{CsCl}+\mathrm{PrCl}_{3}\right| \mid \mathrm{LiCl}-\mathrm{KCl} \\
& \quad-\mathrm{CsCl} \mid \mathrm{Cl}_{2}(\mathrm{C})(-)
\end{aligned}
$$

with the respective EMFs:

$$
\begin{aligned}
& E_{(4)}=E_{\mathrm{Pr}(\mathrm{III}) / \mathrm{Pr}}^{0}+\frac{R \cdot T}{3 \cdot F} \cdot \ln \left(\frac{a_{\mathrm{Pr}(\mathrm{III})}}{a_{\mathrm{Pr}}}\right), \\
& E_{(5)}=E_{\mathrm{Pr}(\mathrm{III}) / \mathrm{Pr}}^{0}+\frac{R \cdot T}{3 \cdot F} \cdot \ln \left(\frac{a_{\mathrm{Pr}(\mathrm{III})}}{a_{\mathrm{Pr}(\mathrm{In})}}\right),
\end{aligned}
$$

where $E_{\mathrm{Pr}(I I I) / P r}^{0}$ is the standard electrode potential of praseodymium; $R$, the universal gas constant; $F$, Faraday constant; $T$, temperature; $a_{\mathrm{Pr}(\mathrm{III})}$, activity of praseodymium ions in the salt phase; $a_{\mathrm{Pr}}$, activity of Pr in pure solid praseodymium (equals to unity); $a_{\operatorname{Pr}(\operatorname{In}) \text {, activity of }}$ 


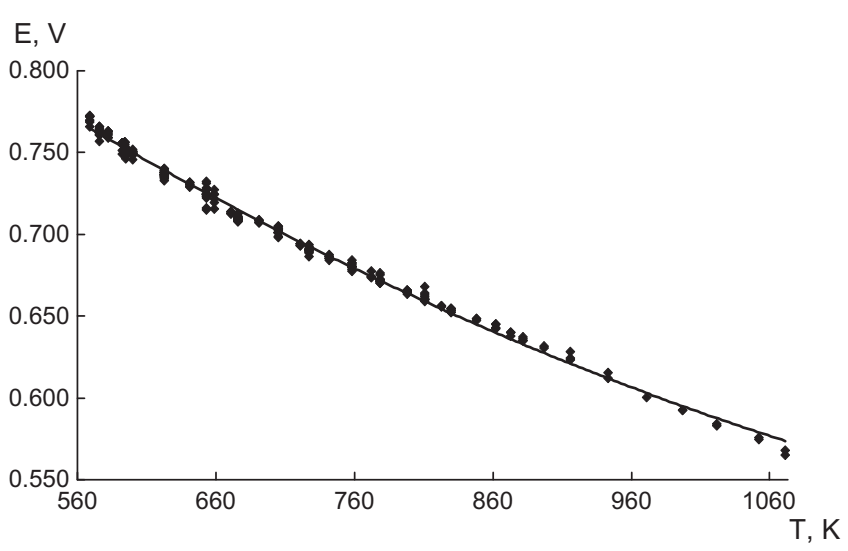

Fig. 2. Temperature dependence of EMF of saturated two-phase Pr-Ga-In alloys.

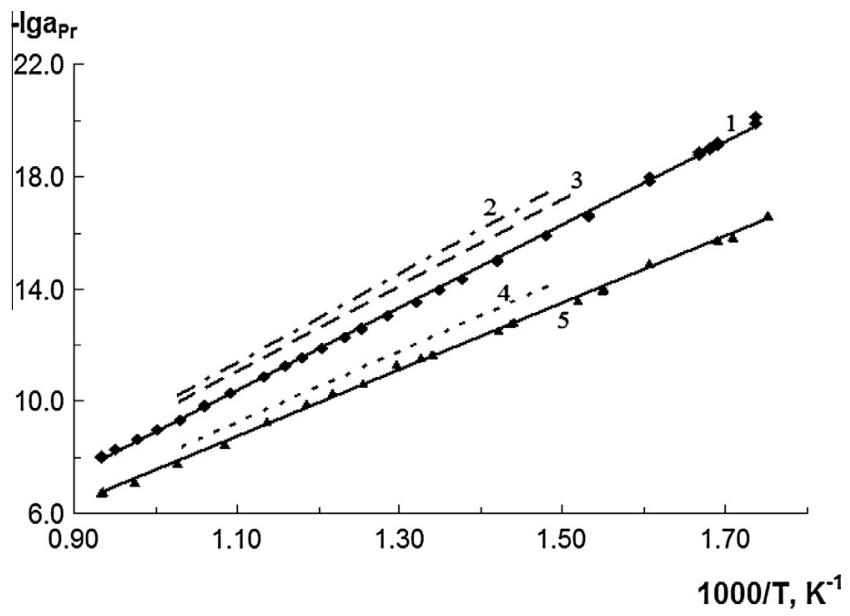

Fig. 3. Activity of $\alpha$-Pr in saturated by praseodymium two-phase alloys: $1-$ In-Ga, present work, 2 - Ga [6], 3 - Ga [5], 4 - In [4,5] (two sets of data are overlaying each other), 5 - In, present work.

Table 1

Partial thermodynamic functions of $\alpha$-Pr in saturated alloys with gallium, indium and Ga-In eutectic.

\begin{tabular}{llllll}
\hline System & $-\Delta \bar{H}_{\operatorname{Pr}}$ & $-\Delta \bar{S}_{\operatorname{Pr}}$ & $-\Delta \bar{G}_{\operatorname{Pr}}$ & $\Delta T(\mathrm{~K})$ & Source \\
& $(\mathrm{kJ} / \mathrm{mol})$ & $(\mathrm{J} / \mathrm{mol} \mathrm{K})$ & $(\mathrm{kJ} / \mathrm{mol})$ & & \\
\hline \multirow{2}{*}{ Ga-Pr } & 303.7 & 116.4 & 210.60 & $675-975$ & {$[6]$} \\
& $293.1 \pm 2.7$ & $110.4 \pm 3.2$ & $204.79 \pm 0.32$ & $663-973$ & {$[5]$} \\
In-Pr & 243.9 & 91.4 & 170.84 & $725-975$ & {$[4]$} \\
& $242.6 \pm 3.1$ & $90.4 \pm 3.7$ & $170.33 \pm 0.37$ & $648-973$ & {$[5]$} \\
& $229.1 \pm 3.4$ & $84.7 \pm 4.4$ & $161.30 \pm 0.69$ & $573-1073$ & Present work \\
Ga-In-Pr & $282.7 \pm 4.4$ & $112.3 \pm 4.9$ & $192.85 \pm 0.70$ & $573-1073$ & Present work \\
\hline
\end{tabular}

praseodymium in the indium based alloy; and 3 is the number of electrons taking part in the electrode reaction. EMF of the galvanic cell (2) can therefore be written as a difference between $E_{(4)}$ and $E_{(5)}$ :

$E_{(2)}=-\frac{R \cdot T}{3 \cdot F} \cdot \ln a_{\mathrm{Pr}(\mathrm{In})}$,

thus giving the following expression for praseodymium activity:

$\lg a_{\operatorname{Pr}(\operatorname{In})}=-\frac{3 \cdot F \cdot E_{(2)}}{2.303 \cdot R \cdot T}$

Activity of $\alpha$-Pr in liquid indium at $573-1073 \mathrm{~K}$, calculated from the Eq. (3), is described by the following equation:

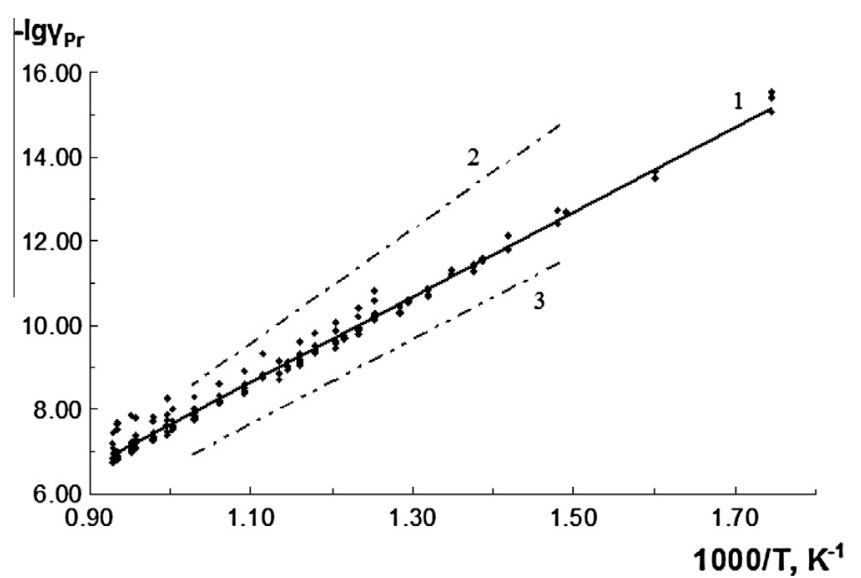

Fig. 4. Temperature dependence of activity coefficients of $\alpha$-Pr in liquid alloys: $1-$ In-Ga, present work; 2 - Ga [6]; 3 - In [4].

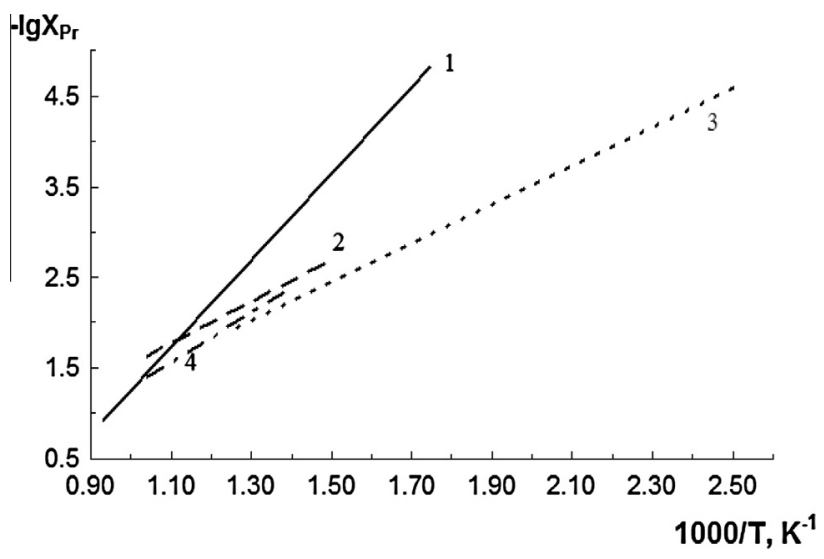

Fig. 5. Solubility of praseodymium in liquid gallium, indium and Ga-In eutectic alloy: 1 - In-Ga, present work; 2 - Ga [6]; 3 - Ga [7]; 4 - In [4].

$\lg a_{\alpha-\operatorname{Pr}(I n)}=4.425-11965 / T \pm 0.026 ;\left(S_{\text {res }}^{2}=0.013\right)$

The obtained data are in good agreement with the reported in the literature for a narrower temperature range $[4,5]$.

Experimentally measured EMF of the galvanic cell (1) was recalculated relative to praseodymium metal, with the appropriate correction for the $\alpha$-Pr $\rightarrow \beta$-Pr phase transition at $1069 \mathrm{~K}$, using the rule of addition of electromotive forces. The resulting values presented in Fig. 2 are described by the following equation:

$$
\begin{aligned}
E= & 1.1145-7.388 \times 10^{-4} T+2.184 \times 10^{-7} T^{2} \pm 0.0057, V ; \\
& \left(S_{\text {res }}^{2}=8.51 \times 10^{-6}, V^{2}\right)
\end{aligned}
$$

Activity of $\alpha$-praseodymium in saturated two-phase Pr-Ga-In alloys in the range of $573-1073 \mathrm{~K}$ was calculated using the procedure described above and can be satisfactorily approximated by the straight line:

$$
\lg a_{\alpha-\operatorname{Pr}(G a-I n)}=5.866-14766 / T \pm 0.190 ;\left(S_{\text {res }}^{2}=9.03 \times 10^{-3}\right)
$$

Comparison of activity of praseodymium in Ga-In eutectic with available literature data on activity of $\alpha$-Pr in liquid gallium $[5,6]$ and indium [4,5] based alloys is presented in Fig. 3. The activity values of $\alpha$-praseodymium in indium obtained in the present study are somewhat higher than given by Degtyar et al. [4] and by Kober et al. [5]. This difference, however, lies within the experimental error, normal for this type of measurements, $c f$. the activity data for Pr in Ga shown in Fig. 3 and taken from Kober et al. [5] and 
Table 2

Excessive thermodynamic functions of $\alpha$-Pr in alloys with gallium, indium and Ga-In eutectic.

\begin{tabular}{|c|c|c|c|c|c|c|}
\hline \multirow[t]{2}{*}{ System } & \multirow{2}{*}{$\begin{array}{l}-\Delta \bar{H}_{\mathrm{Pr}}^{e X} \\
(\mathrm{~kJ} / \mathrm{mol})\end{array}$} & \multirow{2}{*}{$\begin{array}{l}-\Delta \bar{S}_{\mathrm{Pr}}^{e X .} \\
(\mathrm{J} / \mathrm{mol} \mathrm{K})\end{array}$} & \multicolumn{3}{|c|}{$-\Delta \bar{G}_{\mathrm{Pr}}^{e x}(\mathrm{~kJ} / \mathrm{mol})$} & \multirow[t]{2}{*}{ Source } \\
\hline & & & $675 \mathrm{~K}$ & $775 \mathrm{~K}$ & $975 \mathrm{~K}$ & \\
\hline $\mathrm{Ga}-\mathrm{Pr}$ & 259.8 & 102.1 & 190.9 & 180.7 & 160.3 & {$[6]$} \\
\hline In-Pr & 191.7 & 64.1 & 148.4 & 142.0 & 129.2 & [4] \\
\hline Ga-In-Pr & $191.4 \pm 3.8$ & $45.0 \pm 4.2$ & $161.0 \pm 1.5$ & $156.5 \pm 0.9$ & $147.5 \pm 0.6$ & $\begin{array}{l}\text { Present } \\
\text { work }\end{array}$ \\
\hline
\end{tabular}

Vnuchkova et al. [6]. It also should be noted that the literature data were obtained some 20-40 years ago when purity of praseodymium available was lower. Partial thermodynamic functions of $\alpha$ Pr in In and Ga-In eutectic based alloys were calculated, and the results obtained together with the literature data for $\mathrm{Pr}-\mathrm{Ga}$ and Pr-In systems are presented in Table 1.

\subsection{Activity coefficients of praseodymium in $\mathrm{Ga}$-In eutectic alloys}

For determining activity coefficients from the results of EMF measurements the working electrodes in the galvanic cell (1) consisted of unsaturated homogeneous Pr-Ga-In ternary alloys. Praseodymium concentration in the alloys was determined by chemical analysis and $\alpha$-praseodymium was taken as the standard state when calculating activity coefficients. Activity coefficients were determined as the difference between activity and concentration of praseodymium in the alloys:

$\lg \gamma_{\operatorname{Pr}(\mathrm{Ga}-\mathrm{In})}=\lg a_{\mathrm{Pr}(\mathrm{Ga}-\mathrm{In})}-\lg N_{\mathrm{Pr}(\mathrm{Ga}-\mathrm{In})}$,

where $N_{\operatorname{Pr}(G a-I n)}$ is the mole fraction of praseodymium in the liquid alloy.

In the studied temperature range the dependence $\lg \gamma_{\alpha-\mathrm{Pr}}=f(T)$ can be approximated by Eq. (14). Published data on the activity coefficients of $\alpha-\operatorname{Pr}$ in liquid gallium and indium are compared with the experimental results obtained in the present study for Ga-In eutectic alloy in Fig. 4. Activity coefficients of praseodymium in Ga-In eutectic based alloys occupy an intermediate position between those in alloys based on pure gallium (Pr-Ga) and pure indium (Pr-In). At higher temperatures activity coefficients of praseodymium in the eutectic alloy are closer to Pr-Ga system and upon lowering temperature they are gradually shifted towards values of Pr activity coefficients in Pr-In alloys. $\lg \gamma_{\alpha-\operatorname{Pr}(\mathrm{Ga}-\mathrm{In})}=2.351-9996 / T \pm 0.39 ;\left(S_{\text {res }}^{2}=0.0391\right)$

From the values of praseodymium activity, Eq. (12), and activity coefficients, Eq. (14), in Ga-In eutectic it is possible to calculate $\mathrm{Pr}$ solubility in the said alloy. At 573-1073 K praseodymium solubility $\left(X_{\mathrm{Pr}}\right)$ in $\mathrm{Ga}-\mathrm{In}$ is described by the following equation:

$\lg X_{\operatorname{Pr}}=3.515-4770 / T \pm 0.2$

A comparison of published data on solubility of praseodymium in liquid gallium [6,7] and indium [4] with the results obtained in the present work for Ga-In eutectic alloy is presented in Fig. 5. The results obtained in the present work show that at relatively low temperatures (below $830 \mathrm{~K}$ ) solubility of praseodymium in Ga-In eutectic alloy is significantly lower than in pure liquid gallium and indium. Excessive thermodynamic functions of $\alpha$-Pr in $\mathrm{Ga}$, In and Ga-In eutectic based alloys are summarized in Table 2.

\section{Conclusions}

Activity, activity coefficients and solubility of praseodymium in Ga-In eutectic based alloys were determined between 573 and $1073 \mathrm{~K}$ on the basis of the results of EMF measurements. The values of activity coefficients of $\mathrm{Pr}$ in Ga-In eutectic alloys are very close to values of activity coefficients of Pr in alloys with gallium. This indicates the predominant interparticle interaction of Pr with gallium in liquid ternary alloys. Partial and excessive thermodynamic functions of praseodymium in Ga-In based alloys were also determined.

\section{References}

[1] ASM Binary Phase Diagrams, Software, ASM, International (1996).

[2] G. Schwarzebach, G. Flaschka, Complexometric Titration, Khimiya, Moscow, 1970 (in Russian).

[3] Thermal Constants of Substances in: V.N. Glushko, (Ed.), vol. VIII, part 1, USSR Academy of Sciences, Moscow, 1978 (in Russian).

[4] V.A. Degtyar, A.P. Bayanov, L.A. Vnuchkova, V.V. Serebryannikov, Zh. Phys. Khim. 45 (1971) 1816-1817.

[5] V.I. Kober, I.F. Nichkov, S.P. Raspopin, V.M. Kuzminih, Thermodynamic Properties of Metallic Alloys, Part 2, Nauka Kaz. SSR, Alma-Ata, 1989, 67-71, (in Russian).

[6] L.A. Vnuchkova, A.P. Bayanov, V.V. Serebryannikov, Zh. Phys. Khim. 46 (1972) 1051.

[7] S.P. Yatsenko, A. Yu. Anikin, E.N. Dieva, Dokl. Acad. Nauk USSR, Metally Iss. 2 (1972) 212-214 